\title{
Correction: Biomimetic design of protic lipidic ionic liquids with enhanced fluidity
}

Cite this: New J. Chem., 2016, 40, 8970

DOI: $10.1039 / c 6 n j 90043 g$

www.rsc.org/njc
Richard A. O'Brien, ${ }^{a}$ Manuel Sanchez Zayas, ${ }^{\text {b }}$ Stephen T. Nestor, ${ }^{\text {b }}$ Jamie C. Gaitor, ${ }^{\text {b }}$ Lauren M. Paul, ${ }^{c}$ Forrest A. Edhegard, ${ }^{a}$ Samuel Minkowicz, ${ }^{b}$ Richard E. Sykora, ${ }^{a}$

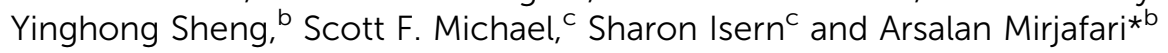

Correction for 'Biomimetic design of protic lipidic ionic liquids with enhanced fluidity' by Richard A. O'Brien et al., New J. Chem., 2016, 40, 7795-7803.

The first name of the fifth author is spelt incorrectly in the published article. The correct author name is Lauren M. Paul. The Royal Society of Chemistry apologises for these errors and any consequent inconvenience to authors and readers.

\footnotetext{
${ }^{a}$ Department of Chemistry, University of South Alabama, Mobile, Alabama 36688, USA

${ }^{b}$ Department of Chemistry and Physics, Florida Gulf Coast University, Fort Myers, Florida 33965, USA. E-mail: amirjafari@fgcu.edu

${ }^{c}$ Department of Biological Sciences, Florida Gulf Coast University, Fort Myers, Florida 33965, USA
} 